\section{$\underset{\substack{\text { hommes } \\ \text { \& migrations }}}{ }$}

\section{Hommes \& migrations}

Revue française de référence sur les dynamiques

migratoires

$1313 \mid 2016$

1983, le tournant médiatique

\title{
Une histoire des racismes et antiracismes
}

Entretien avec Emmanuel Debono, historien, Institut français de

l'éducation, ENS Lyon

\section{Marie Poinsot}

\section{OpenEdition}

\section{Journals}

Édition électronique

URL : http://journals.openedition.org/hommesmigrations/3590

DOI : 10.4000/hommesmigrations.3590

ISSN : 2262-3353

Éditeur

Musée national de l'histoire de l'immigration

Édition imprimée

Date de publication : 1 janvier 2016

Pagination : 146-148

ISBN : 978-2-919040-34-6

ISSN : 1142-852X

\section{Référence électronique}

Marie Poinsot, "Une histoire des racismes et antiracismes », Hommes \& migrations [En ligne], 1313 |

2016, mis en ligne le 17 juin 2016, consulté le 15 septembre 2020. URL : http://

journals.openedition.org/hommesmigrations/3590 


\title{
UNE HISTOIRE DES RACISMES ET ANTIRACISMES
}

\author{
ENTRETIEN AVEC EMMANUEL DEBONO', historien, Institut français de l'éducation, ENS Lyon, \\ réalisé par MARIE POINSOT.
}

\section{Hommes \& Migrations : L'histoire du racisme en France donne-t-elle lieu à de nombreux travaux de recherche? Pourquoi? Quelles sont les sources privilégiées pour étudier ces phénomènes ?}

Emmanuel Debono : Il existe de nombreuses recherches portant sur ce sujet, mais elles ne donnent pas souvent lieu à des publications, si bien qu'en raison des difficultés d'accès à ces travaux, on reste tributaire d'un certain nombre d'études de référence, essentielles mais limitées (on songe à celles de Pierre-André Taguieff ou de Gérard Noiriel, par exemple). L'approche historique me semble toutefois moins florissante que la perspective sociologique, qui travaille sur le présent sans véritablement intégrer l'épaisseur de l'histoire, ce qui est une erreur. II me semble fondamental d'encourager au sein des universités les recherches des étudiants sur ce champ historique, en particulier dans le contexte actuel, où la question du racisme resurgit avec une certaine acuité. Les sources pour étudier le racisme sont nombreuses. Les archives des associations antiracistes historiques - la Ligue des droits de l'Homme (LDH), la Ligue internationale contre le racisme et l'antisémitisme (LICA), le Mouvement contre le racisme et pour l'amitié entre les peuples (MRAP) ou SOS Racisme - attendent les historiens. Celles des syndicats également. Elles recèlent des témoignages, des études, des dossiers juridiques, des comptes rendus qui sont autant de matériaux précieux pour mieux approcher la réalité du racisme et de son emprise sociale au cours des dernières décennies, en France. Il y a aussi d'autres fonds publics (Justice, Intérieur, Éducation nationale...) qui ouvrent bien des horizons.

H\&M: Vous parlez de racismes au pluriel.Y-auraitil plusieurs formes de racisme ? Quels sont les critères ou les facteurs qui les distinguent ? Les racismes sont-ils seulement des opinions ou bien aussi des attitudes et des actes?

E. D. : On a coutume de parler du racisme au singulier, mais il est bien un phénomène pluriel, dans ses cibles comme dans ses expressions. La construction de la figure de l'Arabe ou de celle du Noir, en tant qu'objets de mépris et d'hostilité, s'inscrivent, par exemple, dans des histoires particulières. Elles sont portées par des dynamiques différentes. Si l'on considère, par ailleurs, un type de racisme, il faut aussi tenir compte des discontinuités pour éviter tout contresens historiques : l'antijudaïsme, lui-même évolutif, n'est pas l'antisémitisme du XIXe siècle, qui n'est pas l'antisionisme radical ou ce que certains nomment judéophobie. C'est cette diversité qu'il faut prendre en compte, même si l'on nomme le racisme au singulier, puisqu'il repose sur des ressorts communs tels que le recours aux stéréotypes, le processus d'essentialisation des individus ou encore la réification (le fait d'appréhender une personne comme une chose). Le racisme peut revêtir au moins quatre dimensions : il correspond à des attitudes (opinions, croyances...), des comportements, des discours théoriques ou idéologiques, des modes d'exclusion institutionnalisés (ségrégation, Apartheid...). 
H\&M : Racisme et immigration ont-ils toujours cohabité ? Si on se reporte aux années de flux migratoires importants en France, observe-t-on toujours des poussées de racisme en direction des populations immigrées ? ou de leurs descendants ? Est-ce que le contexte de la société française intervient également ?

E. D. : L'immigration a toujours suscité, de longue date, des réactions de méfiance et de rejet au sein de la population française. Avant qu'elle ne soit perçue comme une menace culturelle, elle représentait d'abord un danger économique, celui d'une concurrence étrangère venant mettre en tension le marché du travail. On parle davantage, à l'origine, de xénophobie que de racisme : c'est l'étranger et la différence dont il est porteur qui font l'objet d'une mise à distance, sans qu'un processus de racialisation intervienne forcément. D’ailleurs, les déchaînements de xénophobie au tournant du XIX ${ }^{e}$ siècle touchent souvent d'abord des Italiens ou des Belges, et, par la suite, des Polonais. Les migrations en provenance d'Afrique du Nord et d'Afrique subsaharienne dans le contexte de décolonisation ont profondément durci le rapport de la société française à l'immigration. Le racisme s'est davantage exprimé, d'autant que s'est progressivement précisée l'idée que l'installation de ces immigrés était définitive (loi sur le regroupement familial de 1976). L'hostilité, voire la haine, a pris pour cible des populations devenues françaises, dont les descendants peinent encore souvent, deux ou trois générations plus tard, à être véritablement considérées comme des Français à part entière. Il faut considérer le contexte sous un angle large : il y a la situation économique, mais d'autres facteurs peuvent expliquer le sentiment d'une libération, à l'heure actuelle, des attitudes xénophobes ou racistes (tensions internationales, peur face à la mondialisation, sentiment de fragilisation des valeurs républicaines...).

H\&M : Peut-on établir une géographie du racisme en France? A-t-elle évolué sensiblement au cours des dernières décennies?
E. D. : La multiplication des facteurs anxiogènes a tendance à dilater le champ géographique du racisme, avec une emprise plus large qu'il y a quelques décennies, quand il se manifestait davantage dans la moitié Est du pays, la France industrielle qui attirait traditionnellement les populations immigrées. Avec les résultats aux dernières élections régionales, on voit bien comme la tolérance aux discours xénophobes est devenue beaucoup plus grande. Ou'il s'agisse de racisme pur ou de formes différentes ou dégradées telles que la xénophobie ou l'ethnocentrisme, on observe la progression de l'opposition du « eux » et " nous ».

H\&M : Quels sont les principaux vecteurs dans la diffusion des racismes en France selon les périodes : les médias, les partis politiques, certains leaders d'opinion ou intellectuels engagés?

E. D. : Ces vecteurs ont toujours coexisté, à l'époque de la grande presse ou de la télévision. Aujourd'hui comme hier, on sait qu'un simple fait divers monté en épingle peut donner lieu à un déferlement de commentaires stigmatisants, opérant sans complexe le passage du particulier au général.

Au plan des médias, Internet constitue en revanche une nouveauté, depuis une vingtaine d'années, par sa capacité à fluidifier la parole raciste, par sa force de persuasion et de diffusion. Son mode de fonctionnement supranational, échappant pour partie aux lois des pays et à celles, en France, interdisant l'expression du racisme, constitue un véritable défi, sinon un casse-tête. Internet véhicule et fait enfler les rumeurs ; il est l'outil idéal pour nourrir les théories du complot, le négationnisme ou encore les processus de radicalisation. On peut toutefois relativiser cette critique en n'oubliant pas qu'Internet est, à l'inverse, un outil d'information et d'éducation incroyable. Le combat semble parfois inégal, l'information et l'éducation sollicitant plus d'efforts que la propagande... 


\section{REPÉRAGE}

H\&M : Les luttes antiracistes sont historiquement structurées. Quels événements fondateurs dans l'histoire de France ont réveillé l'opinion ou des groupes pour résister aux phénomènes racistes ?

E. D. : Le militantisme antiraciste est né de la volonté de défendre l'égale dignité des hommes. Sous sa forme militante, intégrée au mouvement social, il s'est développé au début du XXe siècle, dans le contexte de l'affaire Dreyfus, puis surtout dans les années 1930, en opposition aux exactions dont les juifs étaient l'objet dans certains pays d'Europe centrale et orientale. Auparavant, on sait que l'anti-esclavagisme avait suscité des prises de position dans la société civile et dans le monde politique. Avec la lutte contre l'antisémitisme, l'antiracisme devient militant dans le cadre d'associations qui entendent faire la guerre aux préjugés. II existe déjà toutefois certaines ambiguïtés : on défend volontiers l'émancipation des peuples colonisés sans s'aventurer trop loin au plan politique...

H\&M : Vous avez étudié dans votre thèse " La Ligue internationale contre l'antisémitisme en France (1927-1940) ». Vous avez contribué à l'ouvrage de Gilles Manceron et d'Emmanuel Naquet, Être dreyfusard, hier et aujourd'hui (PUR, 2009) ? Les dynamiques de l'antisémitisme en France dans le passé sontelles très différentes de celles d'aujourd'hui ?

E. D. : Il y a eu une évolution incontestable de l'antisémitisme au cours du XXe siècle. L'antijudaïsme se manifestait encore au début du siècle dernier, alors qu'il ne constitue plus, sauf exception ultra- minoritaire, un courant actuel de la haine des juifs. L'antisionisme rassemble aujourd'hui des franges militantes assez hétéroclites au sein de la société française, à l'extrême droite, à l'extrême gauche et également chez les Français musulmans. Cet antisionisme radical remet au goût du jour certains stéréotypes antijuifs, le vocable de " sioniste » venant se substituer, de manière perverse à celui de « juif », donnant l'illusion d'une critique légitime car portant sur la situation du conflit au Proche-Orient. II y a aussi cet antisémitisme que beaucoup récusent, ne veulent pas voir, relativisent ou nient tout simplement, au prétexte que les juifs ne seraient pas victimes de discriminations, qu'ils auraient donc un statut de « dominants » bénéficiant d'un coupable " philosémitisme d'État ». La réalité est pourtant bien là : l'antisémitisme tue en France, les adultes comme les enfants.

H\&M : Vous êtes chargé d'étude "Éducation et mémoires " à l'Institut français de l'éducation et au Laboratoire de recherche historique Rhône-Alpes (ENS-Lyon). Sur quels thèmes votre étude porte-t-elle pour améliorer la prise en compte des racismes et de l'antisémitisme dans le domaine scolaire?

E. D. : Je travaille depuis la fin de l'année 2015 sur le portail «Éduquer contre le racisme et l'antisémitisme " du ministère de l'Éducation nationale, de l'Enseignement supérieur et de la Recherche. Cet outil vise à proposer des ressources scientifiques et pédagogiques en ligne, à partir du printemps 2016, pour mieux comprendre les expressions racistes et conduire une réflexion active à ce sujet avec les élèves. Fruit d'un travail entre la Direction générale de la scolarité (DGESCO), la Délégation interministérielle à la lutte contre le racisme et l'antisémitisme (DILCRA), Canopé et l'Institut français de l'éducation (ENS de Lyon), première réalisation du genre, le projet s'inscrit dans la grande mobilisation du gouvernement pour les valeurs de la République. Il ne faut pas s'illusionner, un portail ne résout pas tout. Mais on sait qu'il est à même de constituer une étape importante, notamment au plan de la terminologie, dans la constitution du bagage intellectuel délivré par l'institution scolaire et l'espace de réflexion libre mais exigeant qu'elle entend garantir. 